\title{
Simples ?..., pas si simple, tout simplement...
}

Simples, ces plantes médicinales cultivées dans les jardins dits " des simples ", en référence aux remèdes végétaux populaires, à une époque où les religieux étaient tout à la fois curé, maire et médecin... C'est l'époque de l'obscurantisme où pouvoir, magie, croyances et santé étaient imbriqués... Après le siècle des «Lumières » et la révolution industrielle, l'avènement de la chimie de synthèse à fait naître de grands

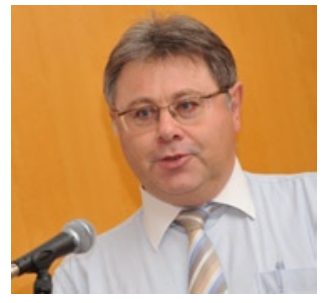
espoirs : la pénicilline, les psychotropes, les antiviraux, les anticancéreux... Las ! Le constat est là : apparition de bactériorésistance, de maladies nosocomiales, de pharmacodépendance, d'effets iatrogènes... et en conséquence de plus en plus de patients se détournent de la médecine conventionnelle symptomatique mécanistique, standardisée, déshumanisée... puis se retournent vers des pratiques parallèles, douces, naturelles, végétales...

La santé est devenue un véritable enjeu économique. Les industriels l'ont bien compris depuis quelques décennies. La tradition a servi de tremplin pour les gélules de poudre de plantes. Le cadre des phytomédicaments est venu leur donner une relative légitimité, tout au moins en France. Puis une politique d'économie de santé s'est traduite par le déremboursement des préparations à base de plantes. Ce fût le rebond des teintures mères végétales toujours remboursées, car rattachées à l'homéopathie... La science est occultée, le business est roi, le marketing exulte, c'est la guerre des formes galéniques (entre poudre, extrait et formes fraîches), les actions commerciales se multiplient, la publicité fait rage... En à peine un demi-siècle, nous sommes passés d'une phytothérapie de tradition à une phytothérapie que l'on peut qualifier de commerciale entretenant la confusion entre tradition et science. L'avènement des compléments alimentaires a accentué le phénomène... Réelles opportunités de business... Les «Super-fruits », leur pouvoir antioxydant exceptionnel, les promesses santé...

Las! L'application du règlement européen relatif aux allégations introduit de nouvelles contraintes (caractérisation des produits, justifications scientifiques)... En clair, moins de profits, moins de retours sur investissements, déception et complaintes de certains... Les syndicats sont appelés en renfort, leurs membres sont aux abois. On crie haro à propos des avis de l'EFSA et des décisions administratives... Les arguments pseudoscientifiques se développent, des groupes de pression se forment, les opérations de lobbying se multiplient... la science est absente du débat... C'est à nouveau un retour de balancier... Eurosceptique ou non, le mouvement de fond est plus global, international...

Parallèlement, la démarche scientifique progresse avec les méta-analyses. Elle laisse entrevoir une phytothérapie plus raisonnée fondée sur l'efficacité 
scientifiquement justifiée. D’autres événements viennent bousculer le « désordre » établi. Les récentes décisions de cassation requalifiant des produits présentés comme compléments alimentaires remettent les questions en jeu... L'analyse stratégique trouve sa raison d'être : comme l'hélicoptère, prendre de l'altitude pour mieux voir la globalité de la problématique. Face aux multiples enjeux actuels, pour beaucoup, il s'agit de prendre des décisions en contexte d'incertitudes... puisse l'allégorie de la caverne ${ }^{1}$ vous éclairer un peu... ce n'est pas simple, tout simplement...

Pr L. Bureau

Institut de formation des acteurs de santé (IFAS), 43, rue du 11-Novembre, F-4913o Les-Ponts-de-Cé, France Correspondance : ifas@orange.fr

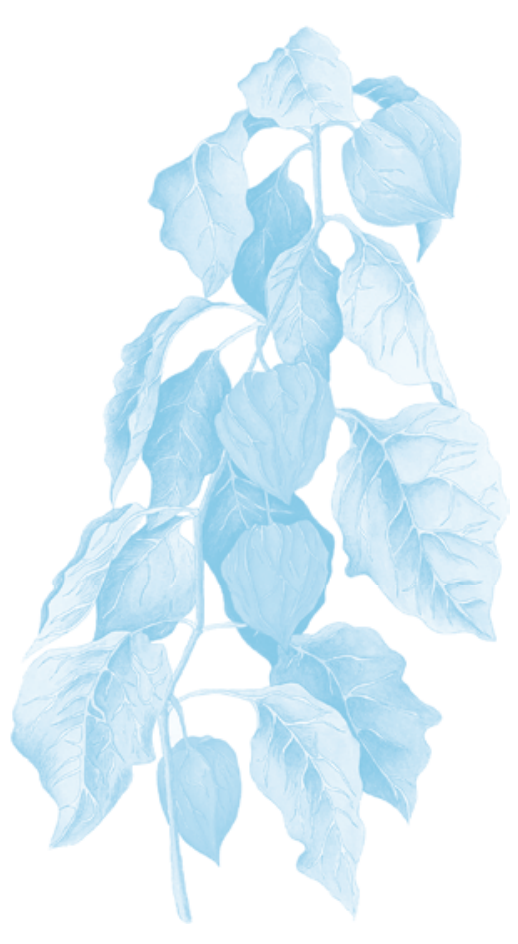

${ }^{1}$ Lire l’article Des simples aux «Super-fruits », lallégorie de la caverne : entre tradition et science, la vision des choses, dans ce numéro. 